\title{
O EMPREENDEDORISMO NA TERCEIRA IDADE: UMA ALTERNATIVA SUSTENTÁVEL À CRISE DA PREVIDÊNCIA SOCIAL?
}

\author{
Denilson Aparecida Leite Freire ${ }^{1}$ \\ Patricia Morilha Muritiba ${ }^{2}$
}

\section{Resumo}

O objetivo desse artigo foi traçar um perfil do empreendedorismo brasileiro na Terceira Idade através do uso da técnica da Análise de Conteúdo dos relatórios do GEM (Global Entrepreneurship Monitor), dos Anuários Estatísticos Previdenciários e dos censos demográfícos do IBGE dos anos de 2002 a 2010. Além disso, fez-se uma análise com os atuais dados da Previdência Social buscando estabelecer uma reflexão dos impactos desse empreendedorismo na economia nacional. Os dados revelaram que o Brasil investe pouco nesse tipo de empreendedorismo, estando em $40^{\circ}$ lugar entre os países da América Latina. Demonstrou, ainda, que a aposentadoria é um dos obstáculos ao empreendedorismo, contudo não o mais importante. Torna-se necessária a elaboração de políticas públicas que subsidiem esse empreendedorismo, podendo se tornar uma das alternativas à crise da Previdência Social e à questão do endividamento dos idosos pelos empréstimos consignados. Sugere-se a inclusão do incentivo ao Empreendedorismo no Estatuto do Idoso.Essa nova lógica alteraria o paradigma de que o envelhecimento do país traria graves consequências negativas à economia, transformando esse envelhecimento em uma fonte de oportunidades.

Palavras chaves: Empreendedorismo. Terceira Idade. Previdência Social.

\section{Abstract}

The aim of this paper was to draw a profile of entrepreneurship in Brazilian Elderly through the use of the technique of content analysis of reports from the GEM (Global Entrepreneurship Monitor), Statistical Yearbook of the Social Security and the IBGE censuses of the years 2002 to 2010. Moreover, an analysis was made with existing data from Social Security in order to establish a reflection of the impact of entrepreneurship on the national economy. The data revealed that Brazil invests little in this type of entrepreneurship, being in 40th place among the countries of Latin America. Has also shown that retirement is one of the obstacles to entrepreneurship, but not the most important. It is necessary to elaborate public policies that support this enterprise, may become an alternative to the crisis of Social Security and the issue of indebtedness of loans charged by the elderly. It is suggested to include the encouragement of entrepreneurship in the Statute of the new logic Idoso.Essa alter the paradigm that the aging of the country would have serious negative consequences to the economy, transforming the aging an opportunity.

Keywords: Entrepreneurship. Third Age. Social Security.

Artigo recebido em $24 / 05 / 2012$

Aprovado em 14/08/2012

\footnotetext{
${ }^{1}$ Doutorando em Administração da Universidade Nove de Julho. Possui Graduação em Administração pelo Centro Universitário Newton Paiva, Mestrado em Administração pela Fundação Cultural Dr. Pedro Leopoldo. Atua como consultor em Gestão de Pessoas e professor universitário.

${ }^{2}$ Professora do Programa de Mestrado e Doutorado em Administração da Universidade Nove de Julho e Pesquisadora-Visitante da Columbia Business School (EUA). Possui graduação em Administração pela Universidade de São Paulo (2001), mestrado em Administração pela Universidade de São Paulo (2005) e doutorado em Administração pela Universidade de São Paulo (2009), com estágio doutoral na Universidade Virginia Tech (EUA). Pesquisadora de gestão estratégica de pessoas; estratégia; gestão de projetos e governança corporativa.
} 


\section{INTRODUÇÃO}

O objetivo desse artigo é revelar qual a relação que se estabelece entre o empreendedorismo e a terceira idade a partir dos dados e informações do GEM(Global Entrepreneurship Monitor).

É sabido que a expectativa de vida no país passou de 51 anos em 1950 para 73 anos na atualidade e que a projeção para 2050 será de 81 anos (IBGE, 2012). Com isso teri-se-a uma inversão da atual pirâmide etária na qual os jovens são a grande maioria. Esse fenômeno brasileiro foi uma resposta direta da família brasileira à situação econômica do país a partir da década de 60 , somada à melhoria da qualidade de vida, da divulgação e uso de métodos contraceptivos e ao ingresso da mulher no mercado de trabalho, segundo Chaimowicz (apud NOVAIS, 2005).

Esse envelhecimento já tem reflexos na economia nacional. Por um lado aumenta o potencial de consumidores e desperta o empreendedorismo para novos negócios focados nesse público alvo. Em 2012, esperava-se que os consumidores com 60 anos ou mais movimentem cerca de $\mathrm{R} \$ 402,3$ bilhões. Esse valor é $45 \%$ maior do que há cinco anos, quando movimentaram R\$ 219 bilhões (IBGE, 2010).

Mas apesar desse reflexo positivo, outros podem impactar negativamente na economia, pois Sete em cada dez aposentados têm renda mensal garantida pela Previdência Social, cujos fundos podem não suportar maior demanda e, somente $20 \%$ da renda deles depende da relação com o mercado de trabalho. Uma alternativa seria abrir novos postos de trabalhos para os idosos, contudo em razão de questões culturais, como a tendência ao abandono do emprego na época da aposentaria e, também, comerciais, já que são poucos os postos de trabalho oferecidos pelas organizações, muitos poucos idosos continuam no mercado de trabalho. Hoje são quase 22,3 milhões de pessoas na chamada terceira idade, dentro os quais 5,4 milhões ainda estão no mercado de trabalho com ou sem carteira assinada (IBGE, 2012).

Outra alternativa seria incentivar o empreendedorismo na Terceira Idade como forma de fomentar a economia nacional e miminizar os reflexos da crise na previdência social. Dessa forma, o objetivo desse artigo foi analisar como que os idosos se caracterizam e se inserem no empreendedorismo no Brasil e quais seus impactos na economia nacional. Através da técnica de Análise de Conteúdo do Global Entrepreneurship Monitor (GEM) do período de 2002 a 2010 e fundamentados pelos dados do Censo do IBGE do mesmo período, pode-se traçar um mapa desse tipo de empreendedorismo a nível nacional.

O GEM consiste em uma avaliação a nível internacional da atividade empreendedora, resultado da parceria entre a London Business School, da Inglaterra, e o Babson College, dos Estados Unidos. No Brasil o órgão responsável pela coleta e processamento dos dados, desde o ano de 2000, é o IBQP (Instituto Brasileiro de Qualidade e Produtividade) em parceria com o SEBRAE (Serviço Brasileiro de Apoio às Micro e Pequenas Empresas).

Sua primeira edição ocorreu no ano de 1999 com a participação de 10 países. Hoje são mais de 80 países que integram a pesquisa que tem como objetivo avaliar a influência do empreendedorismo no crescimento econômico. Além desses resultados, o GEM estuda ainda o comportamento dos indivíduos em relação à criação e gestão de novos empreendimentos, tornando-se assim, uma importante ferramenta de pesquisa na tentativa de melhor compreender esse fenômeno no mundo.

Dentre as variáveis demográficas estudadas pelo GEM está a mensuração do empreendedorismo em relação à faixa etária, revelando as principais questões que acometem os jovens, os adultos e os idosos no contexto empreendedor.

Os resultados apontaram para a necessidade de elaboração de políticas públicas de apoio ao empreendedorismo na Terceira Idade uma vez que esse tipo empreendedorismo no Brasil é ainda tímido e possui vários entraves ao seu desenvolvimento. Com o avanço deste tipo de 
empreendedorismo, os idosos poderiam passar a gerar novos empregos e novas receitas para o país, minimizando os déficits de entrada de recursos na Previdência Social.

Outra questão discutida foi a importância de se criarem estratégias para buscar a redução do endividamentos dos aposentados que realizam empréstimos consignados no país. Algumas sugestões de alternativas poderia ser através da capacitação em empreendedorismo e na conscientização de como efetuar uma gestão mais eficaz do orçamento familiar do idoso.

\section{REFERENCIAL TEÓRICO}

\subsection{Empreendedorismo}

A partir do século XX a noção de empreendedorismo e de inovação tornaram-se construtos complementares. Um dos conceitos originais que focava essa relação, colocava o empreendedorismo como resultante do desequilíbrio provocado pela introdução da inovação no processo econômico. Nesse sentido o empreendedor seria aquele indivíduo capaz de destruir a ordem econômica através da implementação de novos produtos e serviços (SCHUMPETER, 1982).

Mas para que isso ocorra de maneira eficaz é necessário que o empreendedor seja capaz de perceber uma oportunidade e construir uma organização para aproveitá-la. Assim, um novo elemento soma-se ao empreendedorismo: a percepção de saber identificar e aproveitar oportunidades (SALIM; SILVA, 2010), conforme pode ser visto na Figura 1.

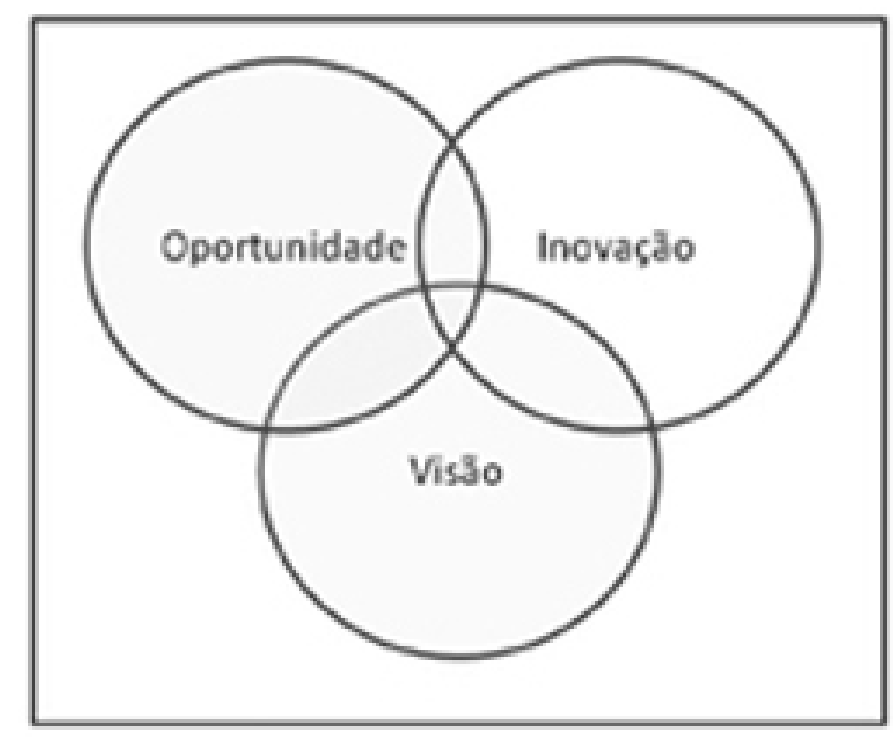

Fonte: Elaborado pelo autor

Figura 1 - Elementos Centrais do Empreendedorismo a partir do Séc. XX

E, para saber identificar oportunidades o empreendedor deve ser capaz de ter visão. Desta forma, hoje, o conceito mais atual de empreendedorismo afirma que o empreendedor é aquela pessoa não somente de imaginar, mas de desenvolver e realizar visões (FILION; DOLABELA, 2000).

Esse conceito também é defendido por William Bygrave, professor do Babson College e um dos fundadores do GEM (Global Entrepreneurship Monitor) que defende o empreendedor como alguém capaz de perceber uma oportunidade e criar uma organização para persegui-la (SALIM; SILVA, 2010). 


\subsection{Teoria Visionária e Oportunidades}

A teoria visionária de Filion (1993) ajuda a entender como se forma uma ideia de empresa e quais elementos que a sustentam. Para esse autor uma das faculdades distintivas que caracterizam o empreendedor reside na sua capacidade de concepção e na definição de contextos, ou seja, a princípio, o lugar que ele quer ocupar no mercado, e em seguida, o tipo de organização que ele precisa para chegar a ocupar o espaço desejado.

Neste contexto, a visão é definida como "uma imagem, projetada no futuro, do lugar que se quer ver ocupado pelos seus produtos no mercado, assim como da imagem projetada do tipo de organização da qual se tem necessidade para consegui-lo" (FILION, 1993, p. 3). O processo visionário acontece da identificação de uma oportunidade que ocorre partir de um processo visionário segmentado três categorias de visões: emergentes, central e complementares.

As visões emergentes são formadas em torno de ideias e conceitos de produtos e/ou serviços imaginados pelo empreendedor, que, frequentemente, antes de se lançar a um empreendimento, pondera várias alternativas de produtos ou serviços. De um processo de seleção entre as visões emergentes resulta a escolha de um produto ou um serviço em particular, que se presta como um esqueleto sobre o qual a visão central é constituída (FILION, 1993).

A visão central é apoiada, em seu desenvolvimento, por uma série de visões complementares, enxertadas em seus componentes interiores e exteriores. Uma visão central raramente continuará a se desenvolver além de um certo ponto, se não tiver esse apoio das visões complementares (FILION, 1993).

Todo o processo visionário tem início a partir da identificação de uma oportunidade. Entretanto, nem todos os empreendimentos são estruturados a partir da real identificação de uma oportunidade, mas pela necessidade de sobrevivência do indivíduo (GEM, 2008).

\subsection{Empreendedorismo por Oportunidade e Necessidade?}

Pode-se analisar o comportamento de empreender a partir de duas perspectivas: a da oportunidade e a da necessidade.

$\mathrm{Na}$ análise a partir da necessidade, percebe-se que o individuo empreende no intuito de satisfazer a uma carência interna, ou seja, um desequilíbrio causado pela manifestação de um déficit na vida dele (LEZANA, 2004).

Diante da perda dos seus empregos ou na tentativa de complementar suas rendas, muitos abrem seus negócios sem realizar uma análise profunda do mercado ou mesmo nem avaliam se eles próprios possuem as habilidades mínimas necessárias para se atuar em um determinado segmento (SEBRAE, 2010).

Assim, para efeitos desse artigo, os empreendedores por necessidade são aqueles que iniciaram um empreendimento por não possuírem melhores opções para o trabalho e que precisam abrir uma empresa a fim de gerar renda para si e suas famílias (GEM, 2008)

Já os empreendedores por oportunidade são aqueles que optaram por iniciar um novo negócio, mesmo quando possuem alternativas de renda. Geralmente empreendem para aumentar ainda mais a sua renda ou pelo desejo de independência no trabalho (GEM, 2008).

O empreendedor, então, nessa perspectiva está sempre em busca de mudança, reage a ela e a explora como sendo uma grande oportunidade (DRUCKER, 2008). A oportunidade deve ser entendida como o potencial para se criar algo novo e que surgiu de um padrão complexo de condições em mudança. Mudanças essas no conhecimento, na tecnologia ou nas condições econômicas, políticas, sociais e demográficas e que tem o potencial de gerar valor econômico (BARON; SHANE, 2007). 
O ideal seria que esse empreendedor fosse capaz de reconhecer uma oportunidade. Entretanto esse processo não é uma habilidade fácil de ser desenvolvida e requer a capacidade de visualizar uma situação futura deseja e avaliar se ela tem, realmente, potencial econômico (SIPILÃ, 2006).

\section{METODOLOGIA}

Trata-se de uma Análise de Conteúdo dos dados dos relatórios do G.E.M (Global Entrepreunership Monitor) dos anos de 2002 a 2010 e disponibilizados no site do órgão. A análise foi complementada com informações disponibilizadas pelo IBGE (2012) referentes aos anos de 2002 a 2010, baseados nos censos demográficos e comportamentais disponibilizados pelo órgão e pelos dados do Anuário Estatístico Previdenciário do ministério da Previdência Social no mesmo período.

Para fins desse trabalho foi considerado idoso o indivíduo com mais de 60 anos de acordo com a lei federal $\mathrm{n}^{\mathrm{o}} 10.741$, de 01 de outubro de 2003 denominada de Estatuto do Idoso.

\section{DISCUSSÃO DOS RESULTADOS}

Em 2012, o Brasil contava com 27 milhões de empresários ou de pessoas que se dizem envolvidas na criação de um negócio próprio, isto é, um em cada quatro indivíduos adultos são empreendedores. Com isso, o Brasil já o terceiro maior mercado do mundo em número de empreendedores no mundo (GEM, 2012).

Do total de empreendedores brasileiros mais da metade dos empresários, cerca de 14,4 milhões, têm entre 25 e 44 anos. Outros 3,4 milhões têm até 24 anos. Seis milhões estão na faixa de 45 a 54 anos, e apenas 3,3 milhões estão na faixa de 55 a 64 anos em 2012.

O Brasil possui um dos menores índices de participação do adulto de meia idade (55-64 anos) no empreendedorismo, possuindo apenas 3\% do total de empreendedores. Isso o coloca na quadragésima posição entre os quarenta e dois países analisados pelo GEM (2011). Ana-lisando os países da América Latina, no ano de 2008, o Chile, por exemplo, contava com $13 \%$ dos empreendedores nesta faixa etária, tem a $1^{\mathrm{a}}$ posição nos países latinos americanos e a $4^{\mathrm{o}}$ mundial nesse ranking (GEM, 2008).

\subsection{Perfil do Empreendedor na Terceira Idade no Brasil}

Analisando-se a evolução história do percentual de empreendedores que iniciaram suas atividades (Empreendedores Iniciais) por faixa etária, percebe-se que a grande maioria dos empreendedores encontra-se na faixa dos 25 aos 44 anos, totalizando 31,4\%, em média, dos pesquisados, no período de 2002 a 2010, como demonstrado na Tabela 1.

\begin{tabular}{|c|c|c|c|c|c|c|c|c|c|c|}
\hline \multirow[b]{2}{*}{ Faixa Etária } & \multicolumn{10}{|c|}{ Taxa (\%) } \\
\hline & 2002 & 2003 & 2004 & 2005 & 2006 & 2007 & 2008 & 2009 & 2010 & Total \\
\hline 18 a 24 & 10,0 & 12,6 & 12,6 & 10,7 & 10,9 & 10,6 & 15,4 & 13,5 & 17,4 & 12,6 \\
\hline 25 a 34 & 18,6 & 16,0 & 17,2 & 14,7 & 16,5 & 14,4 & 12,8 & 17,9 & 22,2 & 16,7 \\
\hline 35 a 44 & 15,2 & 14,4 & 14,7 & 12,1 & 10,7 & 16,1 & 13,7 & 18,7 & 16,7 & 14,7 \\
\hline 45 a 54 & 12,1 & 11,5 & 10,5 & 10,0 & 8,8 & 13,3 & 10,4 & 14,4 & 16,1 & 11,9 \\
\hline 55 a 64 & 6,0 & 3,7 & 7,3 & 2,9 & 6,0 & 4,3 & 3,0 & 6,5 & 9,5 & 5,5 \\
\hline
\end{tabular}

Fonte: GEM (2002:2010)

Tabela 1 - Percentual de Empreendedores Iniciais por Faixa Etária 
Observa-se, ainda que houveram um aumento percentual do número de empreendedores em quase todas as faixas etárias no ano de 2010. O número de empreendedores na Terceira Idade subiu de 6,5\%”em 2009 para 9,5\% em 2010. Entretanto, proporcionalmente, o país ainda tem baixos índices nessa faixa etária.

Um dado interessante é a flutuação dos valores do número de empreendedores na faixa de 55 a 64 anos ao longo dos anos. Tem-se uma variação percentual muito grande de um ano ao outro, por exemplo, os dados demonstram 3,7\% em 2003 passando para 7,3\% em 2004 e regredindo para 2,9\% em 2005 o mesmo acontece nos outros anos, revelando tratar-se de um segmento com alta variabilidade, sendo que uma das possíveis explicações para as variações no período de 2003 a 2005 talvez possa estar atrelada à universalização da previdência social, que garante certa estabilidade econômica, fazendo com que poucos se arrisquem na abertura de novos negócios.

Entretanto, a partir do $2^{\circ}$ ano de aposentadoria, alguns se lançam em novas atividades econômicas no intuito de complementar a renda e desses poucos iniciam um novo empreendimento e destes que o fazem tem alta taxa de mortalidade (SEBRAE, 2004). Essa mesma explicação pode estar afetando as variações futuras evidenciadas.

A análise dos empreendimentos iniciais pode ser dividida em duas dimensões (estágios): nascentes, considerando os empreendimentos com até 3 meses de vida e novos, aqueles de 3 a 42 meses de vida (GEM, 2009), conforme expressa na Tabela 2.

Os dados revelam que os emprendimentos nascentes e novos na Terceira Idade contribuíram com apenas 13,4\% do total de novos negócios no Brasil em 2010, revelando ser um segmento ainda a ser mais bem explorado.

\begin{tabular}{|c|c|c|c|c|c|c|}
\hline \multirow{3}{*}{ Categorias } & \multicolumn{6}{|c|}{ Empreendedores Iniciais } \\
\hline & \multicolumn{2}{|c|}{ Nascentes } & \multicolumn{2}{|c|}{ Novos } & \multicolumn{2}{|c|}{ Total (TEA) } \\
\hline & $\operatorname{Taxa}(\%)$ & Prop. $(\%)$ & $\operatorname{Taxa}(\%)$ & Prop. $(\%)$ & Taxa(\%) & Prop. $(\%)$ \\
\hline 18 a 24 & 6,3 & 24,3 & 6,2 & 22,3 & 17,4 & 22,5 \\
\hline 25 a 34 & 7,3 & 33,9 & 11,8 & 34,3 & 22,2 & 34,4 \\
\hline 35 a 44 & 5,6 & 19,1 & 8,6 & 18,9 & 16,7 & 19,1 \\
\hline 45 a 54 & 5,6 & 17,4 & 8,5 & 16,3 & 16,1 & 16,8 \\
\hline 55 a 64 & 2,3 & 5,2 & 3,8 & 8,2 & 9,5 & 7,2 \\
\hline
\end{tabular}

Fonte: Adaptado de GEM (2010)

Tabela 2 - Características dos Empreendedores Iniciais Segundo Estágio em 2010 (\%)

Dos empreendedores da Terceira Idade, apurou-se que a maioria deles $(5,3 \%)$ investem por oportunidade no ano de 2010 , contra $4,2 \%$ que abriram suas empresas por necessidade. Contudo percebe-se que a razão entre oportunidade e necessidade é ainda muito baixa nas faixas etárias de 45 a 64, sendo maiores nas faixas etárias de 25 a 44 anos, como revelam os dados da Tabela 3. 


\begin{tabular}{l|c|c|c|c|c}
\hline \multicolumn{1}{c}{ Tipo de } & \multicolumn{5}{c}{ Faixa Etária } \\
\cline { 2 - 6 } \multicolumn{1}{c|}{ Atividade } & $\mathbf{1 8 - 2 4}$ & $\mathbf{2 5 - 3 4}$ & $\mathbf{3 5 - 4 4}$ & $\mathbf{4 5 - 5 4}$ & $\mathbf{5 5 - 6 4}$ \\
\hline Comércio Varejista & 33 & 28 & 21 & 20 & 20 \\
\hline Ind. Transformação & 3 & 13 & 8 & 18 & 8 \\
\hline Alimentação & 9 & 13 & 18 & 21 & 36 \\
\hline Atividades Serv. Coletivo & 9 & 6 & 11 & 2 & 4 \\
\hline Atividades Imobiliárias & 15 & 14 & 15 & 5 & 16 \\
\hline Construção & 8 & 6 & 5 & 5 & 8 \\
\hline Transporte/Armazenagem & 7 & 4 & 2 & 2 & 4 \\
\hline Venda/Man. Veículo & 5 & 4 & 5 & 9 & - \\
\hline Comércio Atacadista & - & 2 & 2 & 2 & - \\
\hline Residência com Empregados & 9 & 6 & 13 & 7 & 4 \\
\hline
\end{tabular}

Fonte: GEM (2010)

Tabela 3 - Empreendedores Iniciais por Motivação Segundo Faixa Etária e Razão Oportunidade/Necessidade em $2010(\%)$

Ao longo do período de 2002-2008, a participação da terceira idade no empreendedorismo por necessidade teve uma redução, representando apenas $6 \%$ dos empreendedores no período e regredindo para $4,2 \%$ em 2010.

Um das possíveis explicações dessa redução pode ser a tendência de universalização da previdência, fazendo com que os aposentados consigam manter sua subsistência, reduzindo assim as alternativas de complementação de renda no mercado de trabalho (GEM, 2010).

Já o empreendedorismo por oportunidade que vinha reduzindo, aumentou para 5,3\% talvez em função que daqueles aposentados que não sofreram a influência dos fatores da previdência e que realmente decidiram investir em outra fonte de renda procuraram alternativas mais viáveis e não focaram apenas nas suas necessidades.

Descobriu-se que a grande maioria dos empreendedores na Terceira Idade atua preferencialmente nas atividades ligadas à Alimentação (36\%), Comércio Varejista (20\%) e na Construção (16\%) como demonstrado na Tabela 4. Observa-se que os dois primeiros segmentos dizem respeito ao setor de serviços e mesmo no setor da construção a maior atuação dos novos empreendimentos dizem respeito às atividades como marceneiro, eletricista, encanador, dentre outras, configurando-se, também, serviços à construção (GEM, 2010).

\begin{tabular}{l|c|c|c|c|c}
\hline \multicolumn{1}{c}{ Tipo de } & \multicolumn{5}{c}{ Faixa Etária } \\
\cline { 2 - 6 } \multicolumn{1}{c|}{ Atividade } & $\mathbf{1 8 - 2 4}$ & $\mathbf{2 5 - 3 4}$ & $\mathbf{3 5 - 4 4}$ & $\mathbf{4 5 - 5 4}$ & $\mathbf{5 5 - 6 4}$ \\
\hline Comércio Varejista & 33 & 28 & 21 & 20 & 20 \\
\hline Ind. Transformação & 3 & 13 & 8 & 18 & 8 \\
\hline Alimentação & 9 & 13 & 18 & 21 & 36 \\
\hline Atividades Serv. Coletivo & 9 & 6 & 11 & 2 & 4 \\
\hline Atividades Imobiliárias & 15 & 14 & 15 & 5 & 16 \\
\hline Construção & 8 & 6 & 5 & 5 & 8 \\
\hline Transporte/Armazenagem & 7 & 4 & 2 & 2 & 4 \\
\hline Venda/Man. Veículo & 5 & 4 & 5 & 9 & - \\
\hline Comércio Atacadista & - & 2 & 2 & 2 & - \\
\hline Residência com Empregados & 9 & 6 & 13 & 7 & 4 \\
\hline
\end{tabular}

Fonte: Adaptado de GEM (2010)

Tabela 4 - Empreendedores Iniciais por Setor de Atividade e Faixa Etária - 2010 (\%)

Em relação ao tempo de escolaridade os dados revelaram que os empreendedores com até 4 anos de estudos empreendem mais por necessidade, já os com mais de 5 anos empreendem 
por oportunidade conforme demonstrado no Gráfico 1, demonstrando que a escolaridade influencia no tipo de empreendedorismo.

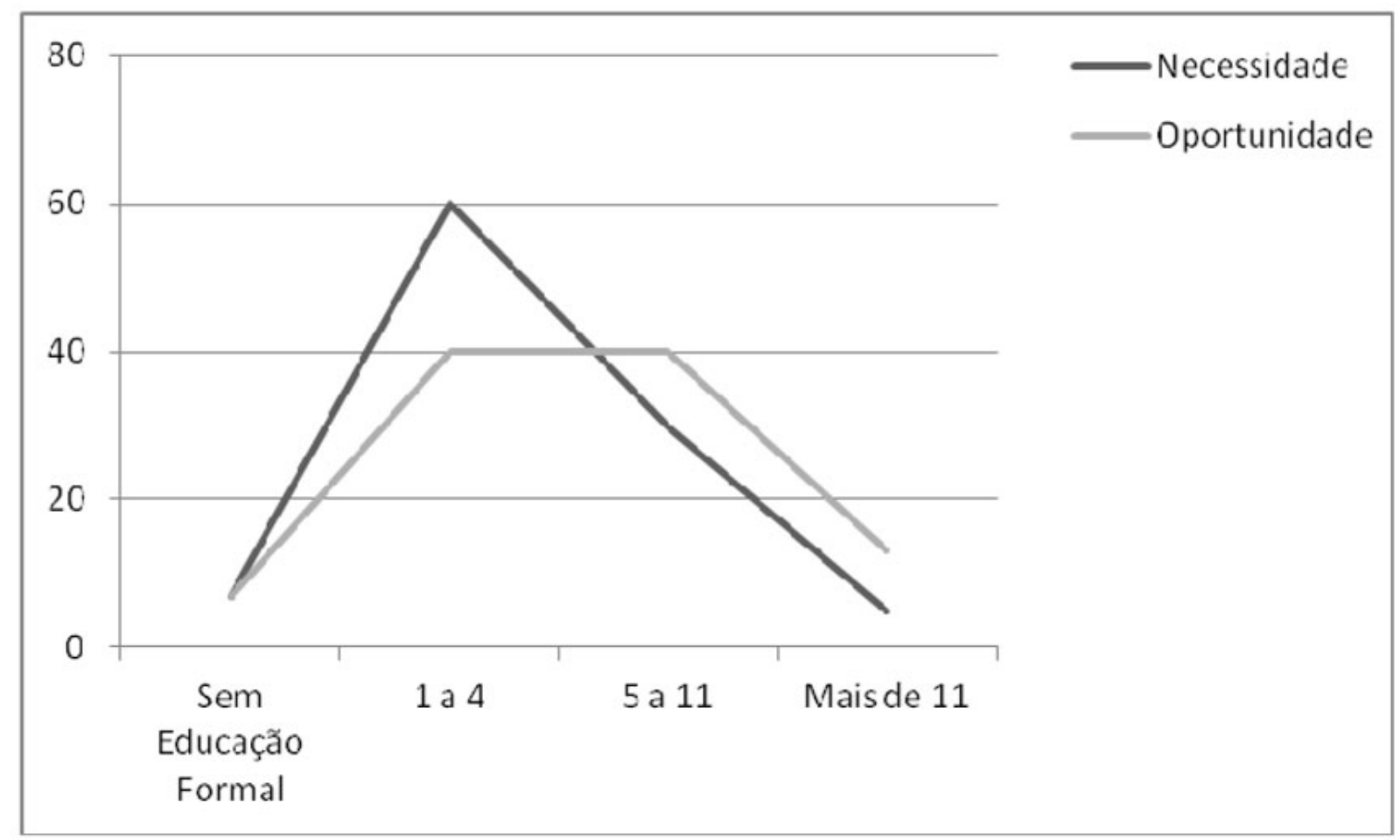

Fonte: Elaborado a parti de GEM (2002:2008)

Gráfico 1 - Empreendedorismo na Terceira Idade por Motivação segundo Escolaridade de 2001 a 2008.

Em síntese, o Quadro 1 traça o perfil do empreendedor de oportunidade e necessidade na terceira idade, apuradas no ano de 2008.

\begin{tabular}{|c|c|c|c|}
\hline Tipo & Características & $\begin{array}{c}\text { Instrumentos de } \\
\text { Apoio }\end{array}$ & $\begin{array}{c}\text { Políticas } \\
\text { Existentes no } \\
\text { Brasil }\end{array}$ \\
\hline Idoso por Necessidade & $\begin{array}{l}6 \% \text { dos Emrpreendedores Brasileiros } \\
100 \% \text { renda de } 1 \text { a } 3 \text { salários mínimos } \\
60 \% \text { com escolaridade até } 4 \text { anos } \\
40 \% \text { concentrados em serviços } \\
\text { orientados ao consumidor }\end{array}$ & $\begin{array}{l}\text { Programas Sebrae } \\
\text { Programa Midias }\end{array}$ & - \\
\hline Idoso por Oportunidade & $\begin{array}{l}2 \$ \text { dos empreendedores Brasileiros } \\
33 \% \text { renda de } 1 \text { a } 3 \text { salários mínimos } \\
40 \% \text { com escolaridade de } 5 \text { a } 11 \text { anos } \\
44 \% \text { concentrados em serviços } \\
\text { orientados ao consumidor }\end{array}$ & $\begin{array}{l}\text { Incubadores } \\
\text { Rede universidade } \mathrm{x} \\
\text { empresas }\end{array}$ & - \\
\hline
\end{tabular}

Fonte: Adaptado de GEM (2008)

Quadro 1 - Características dos Empreendedores e as Políticas de Apoio à Terceira Idade 2008

Analisando-se os segmentos em que mais houveram investimentos dos empreendedores na Terceira Idade, apurou-se que os indivíduos que investiram por necessidade nessa faixa etária possuem de um a quatro anos de estudo e suas atividades são orientadas para os consumidores. 
Já os empreendedores por oportunidade têm um maior nível de escolaridade, normalmente formação universitária, ou experiência qualificada e está disposto a enfrentar novos desafios. Entretanto assim como nos empreendedores por oportunidade suas atividades estão voltadas para serviços especializados a consumidores, à indústria de transformação, às empresas, como consultorias e serviços técnicos especializados (GEM, 2008).

O Quadro 1 revela também que o idoso conta com poucos instrumentos de apoio, como os programas do Sebrae e programas elaborados pela parceria de universidades empresas. Fica evidente, entretanto, a falta de políticas e programas de apoio governamental ao empreendedorismo na Terceira Idade o que já ocorre com o empreendedorismo voltado para os jovens no Brasil como: programa do Primeiro Emprego, programa ProJovem Trabalhador do Ministério do Trabalho e o programa Jovem Empreendedor do Sebrae.

\subsection{Análise dos Dados da Previdência Social}

A evolução do número de indivíduos de 2001 a 2009, revelou que a faixa etária de 50 a 59 anos de idade passou de $6,5 \%$ em 2002 para $8,11 \%$ em 2009 e os que tinham mais de 60 anos de 3,56\% em 2001 para 3,99\% em 2009 conforme demonstra o Gráfico 2.

Os dados mais recentes do Censo 2010 do Instituto Brasileiro de Geografia e Estatística (IBGE, 2012) mostram que o Brasil possuía cerca de 190 milhões de indivíduos, com 22 milhões de indivíduos com mais de 60 anos, representando $11,57 \%$ da população brasileira e esse percentual pode chegar a $29,75 \%$ em 2050 .

O regime geral de Previdência Social apontou que em 2011 tinha 29 milhões de aposentados e pensionistas. Desse total, 1,1 milhões eram funcionários públicos federais aposentados e militares reformados.

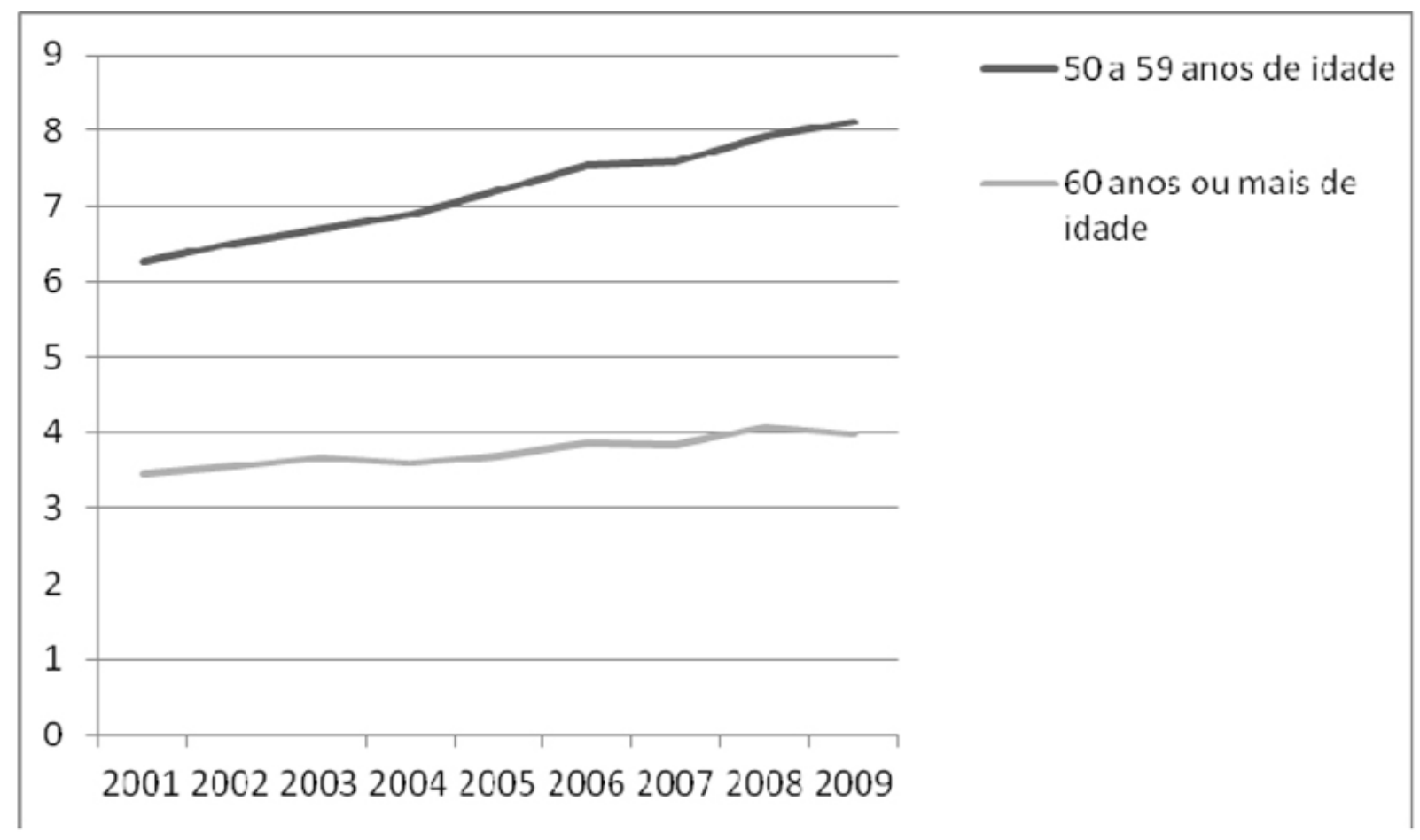

Fonte: elaborado a partir do PNAD (2010)

Gráfico 2 - Evolução do Percentual de Indivíduos por Faixa Etária no Brasil de 2001 a 2009 
$\mathrm{Na}$ esfera federal, a receita estava em R $\$ 24$ bilhões e a despesa em R $\$ 80$ bilhões, ocasionando um déficit de R $\$ 56$ bilhões. Os valores médios mensais por funcionário aposentado eram de R \$ 6.060,00, isto é, próximo a 12 salários mínimos. Nessa modalidade apenas o funcionário desconta para a Previdência Social (AEPS, 2012).

Em relação aos funcionários urbanos, com regime CLT, havia 22 milhões de trabalhadores aposentados ou pensionistas. A receita girou em torno de $\mathrm{R} \$ 246$ bilhões, com despesa de R \$ 225 bilhões, gerando, assim, um superávit de R $\$ 21$ bilhões. Os valores médios mensais eram de apenas $\mathrm{R} \$ 786,00$ por trabalhador aposentado, ou seja, 1,3 salários mínimos. Nessa modalidade, empresa e empregado contribuem para a Previdência Social (AEPS, 2012).

Há, ainda, mais 6,2 milhões de pessoas que recebem benefícios pela Previdência rural, com uma receita de $\mathrm{R} \$ 5,5$ bilhões e uma despesa de $\mathrm{R} \$ 61,1$ bilhões, gerando um déficit de $\mathrm{R} \$ 55,6$ bilhões. Os valores médios mensais estão em torno de $\mathrm{R} \$ 758,00$ por trabalhador aposentado ou 1,3 salários mínimos (AEPS, 2012).

Desta forma as contas da Previdência Social não fecham e podem ser agravadas com o passar dos anos, uma vez que menos pessoas irão contribuir para a geração de receitas e mais pessoas irão requerer os seus benefícios (saídas de caixa).

\section{CONSIDERAÇÕES FINAIS}

Hoje o Governo se preocupa mais em como reduzir a saída de recursos da Previdência Social tendo ações, como por exemplo, prorrogando o número de anos para se aposentar. O foco deveria estar na geração de novas receitas e os próprios idosos poderiam contribuir para a geração de novos empregos e, consequentemente, novas receitas para a Previdência Social.

O ideal é que houvesse políticas públicas de apoio ao empreendedorismo na Terceira Idade e que fossem esses empreendedores a destinarem produtos e serviços à sua faixa etária. Entretanto, como analisado anteriormente, o empreendedorismo na terceira idade no Brasil é ainda tímido e possui vários entraves ao seu desenvolvimento. Com o avanço deste tipo de empreendedorismo, os idosos poderiam passar a gerar novos empregos e novas receitas para o país.

Com um grande número de aposentados disponíveis no mercado, não faltam empresas dispostas a investir nesse segmento. Entretanto, há também organizações que, de olho na regularidade dos pagamentos recebidos pelos aposentados efetuam empréstimos consignados.

Existem em todo o País 56 milhões de contratos firmados de empréstimo consignados. Esse mercado movimenta atualmente $\mathrm{R} \$ 120$ bilhões e levanta preocupações principalmente por causa do endividamento dos aposentados que usam essa modalidade de empréstimo.

Segundo Informações do Instituto Nacional de Seguridade Social somente em 2012 aposentados e pensionistas contraíram $\mathrm{R} \$ 28,4$ bilhões em dívidas na modalidade de crédito consignado. A margem consignável do empréstimo pessoal é limitada a 30\% da remuneração líquida desse público alvo.

$\mathrm{Na}$ faixa salarial de um a três salários mínimos, os empréstimos pessoais tiveram como valor médio $\mathrm{R} \$ 3,3$ mil e, na contratação via cartão de crédito, $\mathrm{R}$ \$ 570,40. Já na faixa acima de três salários mínimos, o valor médio de cada empréstimo na modalidade de crédito pessoal e cartão de crédito foram $\mathrm{R} \$ 6$ mil e $\mathrm{R} \$ 729$, respectivamente.

Sendo assim poder-se-ia pensar em estratégias para buscar a redução do número de empréstimos consignados no país, hoje uma grande preocupação do governo. Alguns exemplos de estratégias poderiam ser através da capacitação em empreendedorismo e na conscientização de como efetuar uma gestão mais eficaz do orçamento familiar via investimentos na própria economia nacional.

Os artigos 26 a 28 do Estatuto do Idoso (2004) informa que é direito do idoso exercer 
uma atividade profissional, aproveitando seus potenciais e habilidades e estimular as empresas privadas na a admissão desses profissionais:

Art. 26. O idoso tem direito ao exercício de atividade profissional, respeitadas suas condições físicas, intelectuais e psíquicas.

Art. 27. Na admissão do idoso em qualquer trabalho ou emprego, é vedada a discriminação e a fixação de limite máximo de idade, inclusive para concursos, ressalvados os casos em que a natureza do cargo o exigir.

Parágrafo único. O primeiro critério de desempate em concurso público será a idade, dando-se preferência ao de idade mais elevada.

Art. 28. O Poder Público criará e estimulará programas de:

I - profissionalização especializada para os idosos, aproveitando seus potenciais e habilidades para atividades regulares e remuneradas;

II - preparação dos trabalhadores para a aposentadoria, com antecedência mínima de 1 (um) ano, por meio de estímulo a novos projetos sociais, conforme seus interesses, e de esclarecimento sobre os direitos sociais e de cidadania;

III - estímulo às empresas privadas para admissão de idosos ao trabalho.

Entretanto, sugere-se incluir no art. 28 uma cláusula sobre a estruturação e implantação programas de incentivo ao empreendedorismo na Terceira Idade.

Este artigo não pretende fazer nenhuma apologia política e retirar ou minimizar a culpa dos governantes pela situação caótica da Previdência Privada, antes busca sugerir soluções para minimizar seus impactos negativos na economia nacional.

Essas ações propostas inverteriam a lógica do pensamento atual de que o envelhecimento do Brasil trará grande consequências econômicas em virtude da falta de mão-de-obra ou da falta investimentos em novas demandas internas, isto é, transformaria uma possível crise em uma grande oportunidade.

\section{REFERÊNCIAS BIBLIOGRÁFICAS}

BARON, R. A.; SHANE, S. A. Empreendedorismo: Uma Visão do Processo. São Paulo: Thomsom Learning, 2007.

BRASIL. Estatuto do idoso: lei federal n ${ }^{\circ}$ 10.741, de 01 de outubro de 2003. Brasília, DF: Secretaria Especial dos Direitos Humanos, 2004.

DRUCKER, P. F. Inovação e Empreendedorismo (Entrepreneurship): Práticas e Princípios. São Paulo: Cengage Learning, 2008.

FILION, L. J; DOLABELA, F. C. Boa Ideia! E Agora. São Paulo: Cultura Editores Associados, 2000 .

FILION, Louis Jaques. Visão e Relações: elementos para um metamodelo empreendedor. Revista de administração de empresas, São Paulo, 33(6), p. 50-61, nov/dez. 1993.

GEM - Global Monitor Entrepreneurship. Empreendedorismo no Brasil - 2008. Curitiba: Instituto Brasileiro de Qualidade e Produtividade no Paraná,2008.

Empreendedorismo no Brasil - 2008. Curitiba: Instituto Brasileiro de Qualidade e Produtividade no Paraná,2009.

Empreendedorismo no Brasil - 2009. Curitiba: Instituto Brasileiro de Qualidade e Produtividade no Paraná,2010. 
BRASIL. MPAS. INSS. DATAPREV. Anuário estatístico da previdência social - AEPS 2011. Brasília,2012. 870 p.

IBGE (ed.). Pesquisa Nacional por Amostra de Domicílios - PNAD de 2010. Rio de Janeiro, Ministério do Planejamento e Orçamento, 2010. 288p.

IBGE. Anuário Estatístico do Brasil, 2010.

LEZANA, A. G. R. Fundamentos do empreendedorismo. Florianópolis: UFSC/PPGEP. Proferido em aula, out. 2004.

NOVAIS, Raquel Carvalho. Baby Boomers na Terceira Idade, uma oportunidade de mercado: um estudo da indústria de cosméticos Natura. In: CONGRESSO BRASILEIRO DE

SALIM, C. S.; SILVA, N. C. Introdução ao Empreendedorismo: Despertando a Atitude Empreendedora. São Paulo: Elsevier, 2010.

SCHUMPETER, Josef A. Teoria do Desenvolvimento Econômico. São Paulo: Abril Cultural, 1982. $168 \mathrm{p}$.

SEBRAE. Fatores condicionantes e Taxa de mortalidade de empresas no Brasil. Relatório de Pesquisa. 2004.

SIPILÄ, M. Opportunity Recognition in Entrepreneurial Studies. Seminar in Business Strategy and International Business, 2006. Disponível em: http://www.tuta.hut.fi/studies/ Courses_and_schedules/Isib/TU-91.167/seminar_papers_2006/Miika_Sipila.pdf. Acesso em: 14 nov. 2006. 